\title{
Roy Hart Theatre Ontem, Hoje e Amanhã: Entrevista com Kaya Anderson ${ }^{1}$
}

Roy Hart Theatre Yesterday, Today and Tomorrow:
Interview with Kaya Anderson

Por: Massimiliano Buldrini2

Tradução: Claudia Venturi ${ }^{3}$ 


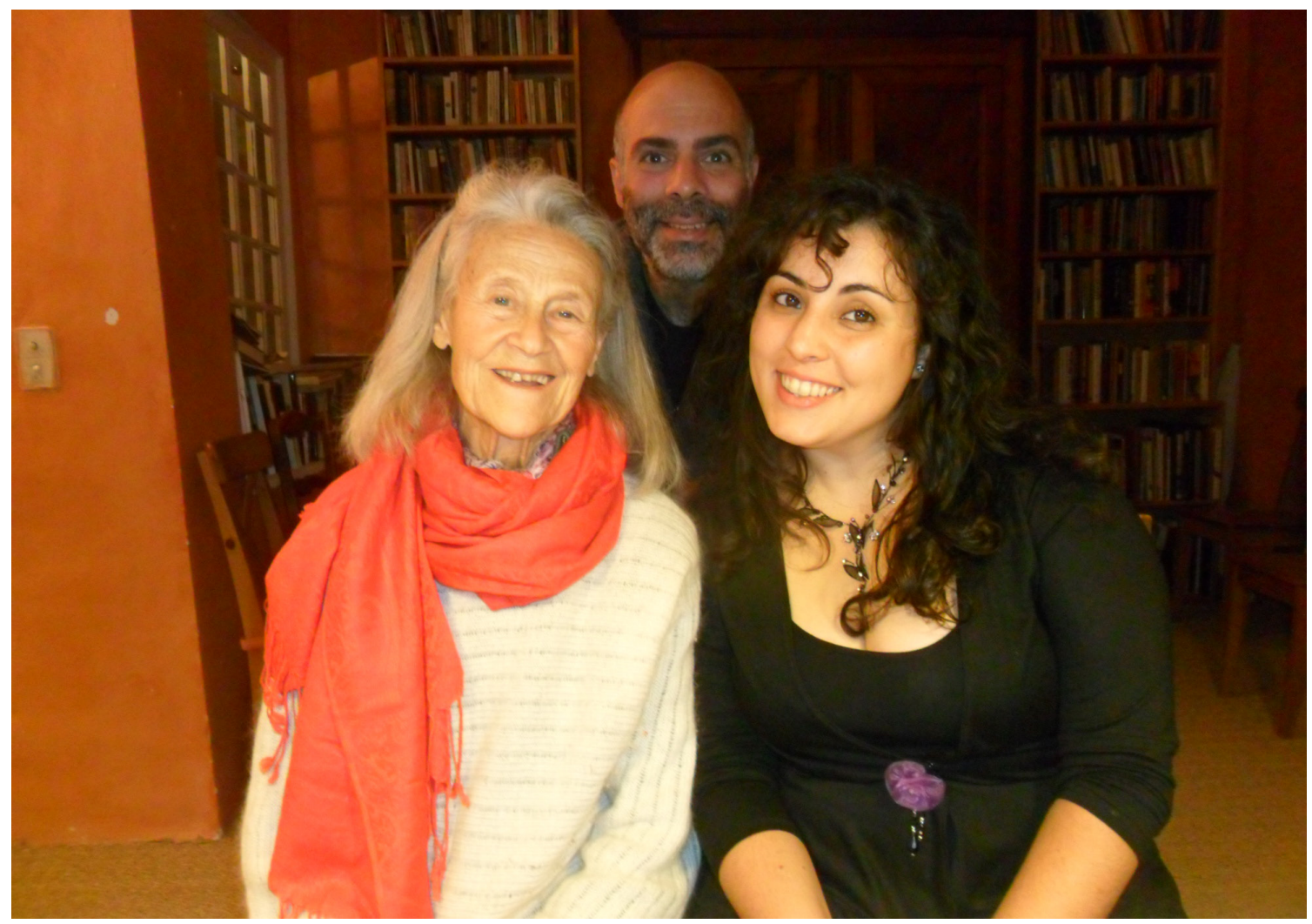

Entrevista com Kaya Anderson em 16 de maio de 2015, no Centre Artistique International Roy Hart (CAIRH), em Malérargues, França. Imagem: Kaya Anderson, Massimiliano Buldrini e Paula Noeglia Cianfagna. Foto: Ivan Midderigh.

ISSN: 1414.5731

E-ISSN: 2358.6958

\footnotetext{
${ }^{1}$ Kaya Margaret Anderson (1932-) é atriz, cantora e professora de canto e técnica vocal. É uma das fundadoras do Roy Hart Theatre em Londres e do CAIRH em Malérargues, França.

${ }^{2}$ Ator, diretor, músico, professor e pesquisador vocal. Bacharel em Antropologia Teatral pelo DAMS (Universidade de Bolonha). Mestrando junto ao Programa de Pós-graduação em Teatro, PPGT/CEART/UDESC. Bolsista FAPESC.

E-mail: maxbuldrini@gmail.com

${ }^{3}$ Atriz, diretora, professora de teatro, professora e tradutora de italiano. Bacharel em Artes Cênicas pela PUC Paraná (1993). Mestre em Educação pela UFSC (2007). Especialista em Teatro Social pela Università Cattolica di Milano (IT).

E-mail: claudiaventuri@yahoo.com
} 


\section{Uma breve contextualização}

por Maria Brígida de Miranda ${ }^{4}$

De março a julho de 2015, o ator de commedia dell'arte e pesquisador vocal Massimiliano Buldrini realizou uma intensa pesquisa de campo para sua dissertação de mestrado no Centre Artistique International Roy Hart (CAIRH), em Malérargues, França. O renomado centro de pesquisa vocal, uma "associação democrática"5 e sem fins lucrativos, foi criado em 1991 como desdobramento da companhia Roy Hart Theatre ${ }^{6}$, formada em 1968 e liderada pelo ator sul-africano Roy Hart (1926-1975).

Ator de formação clássica7, Hart destacou-se posteriormente como pesquisador vocal quando aluno do professor de canto e inovador pesquisador vocal Alfred Wolfsohn (1896-1962) nas décadas de 1950 e 1960. As pesquisas de Wolfsohn e Hart, explorando as conexões entre a voz humana e psiqué, ampliaram as noções sobre o potencial e a expressividade da voz. Em 1956 Hart reuniu um grupo de jovens atores e atrizes interessados na pesquisa da expansão do espectro vocal, com os quais desenvolveu novas concepções e práticas para o treinamento de vocal. Com produções teatrais "legendárias" ${ }^{8}$ e palestras sobre a expansão do espectro vocal humano nas áreas de teatro e psicoterapia, Hart e sua companhia despertaram o interesse da classe teatral europeia e seus expoentes como "Jerzy Grotowski, Peter Brook e Auther Koestler" ${ }^{\prime \prime}$. Entre 1974 e 1975, um grupo de mais de 40 atores e atrizes, liderados pelo empreendedor Hart, mudou-se para as ruínas do Château de Malérargues ${ }^{10}$.

Atualmente a propriedade rural do CAIRH destaca-se internacionalmente, não apenas por ser a guardiã do legado de Hart e Wolfsohn e por abrigar em seus chalês os membros da lendária companhia teatral, mas também por sediar uma dinâmica escola de treinamento vocal que reúne em cursos e seminários, pesquisadores reconhecidos como Linda Wise, Enrique Pardo e Kaya Anderson ${ }^{11}$.

Durante os quatro meses que residiu na bucólica sede, Buldrini conviveu diariamente com os fundadores remanescentes do grupo de teatro. Neste período realizou entrevistas com Kaya Anderson, Ian Magilton, Paul Silber e Clara Silber-Harris. A entrevista com a atriz, cantora, pesquisadora e professora de voz, Anderson, de quem Buldrini foi aluno e cuidador, mostra-se como uma conversa aberta e tranquila onde Anderson, hoje com 83 anos, fala a Buldrini do início da pesquisa sobre a voz humana no Instituto de Alfred Wolfsohn; das aventuras e percalços da mudança da comunidade artística de Hart da Inglaterra para o sul da França; dos desafios e transformações nas pesquisas vocais a partir da morte prematura de Hart; da saída de vários

\footnotetext{
4 Atriz, diretora, e pesquisadora teatral. Doctor of Philosophy pela La Trobe University, Austrália. Professora Associada do Departamento de Artes Cênicas e do Programa de Pós-graduação em Teatro da Universidade do Estado de Santa Catarina (UDESC). E-mail: brigidademiranda@gmail.com 5 <http://www.roy-hart-theatre.com/site/cairh/> acesso em 10 de novembro de 2015.

6 Para saber mais sobre o Roy Hart Theatre consulte a página da companhia no site oficial do CAIRH. <http://www.roy-hart-theatre.com/site/the-roy-hart-theatre/> acesso em 10 de novembro de 2015.

7 Hart estudou na Royal Academy of Dramatic Art (R.A.D.A.), em Londres. Site oficial do CAIRH <http://www.roy-hart-theatre.com/site/roy-hart/> acesso em 10 de novembro de 2015.

8 Paul Silber usa o termo "legend" para descrever o impacto causado no público do Festival de Nancy em 1969 ao assistir a primeira produção do Roy Hart Theatre, As Bacantes de Eurípedes. <http://www.roy-hart-theatre.com/site/the-roy-hart-theatre/> . Acesso em 10 de novembro de 2015.

9 Site oficial do CAIRH <http://www.roy-hart-theatre.com/site/roy-hart/> acesso em 10 de novembro de 2015.

10 Para obter mais informações sobre a história da reconstrução do Château pela companhia Roy Hart Theatre acesse <http://www.roy-hart-theatre.com/site/ malerargues/history/>. Acesso em 10 de novembro de 2015.

11 Acesse a lista completa dos pesquisadores professores do CAIRH em <http://www.roy-hart-theatre.com/site/people/teachers/>. Acesso em 10 de novembro de 2015.
} 
membros da companhia nos anos seguintes e do trabalho que ela desenvolve hoje unindo práticas meditativas e marciais chinesas na sua rotina de práticas psicofísicas.

Anderson em entrevista concedida a Buldrini. Sede do CAIRH, Château de Malérargues, França, 16 de maio de 2015.

Estou aqui com Kaya Anderson para uma entrevista, gentilmente concedida para que possa ser inserida em meu projeto de Mestrado, na Universidade do Estado de Santa Catarina (UDESC), em Florianópolis, Brasil.

Ok, então, eu sou Kaya Anderson, como já foi dito, e iniciei este trabalho com Alfred Wolfsohn e Roy Hart em 1956, só para começar. Max gostaria de saber por que... Eu sei que você tinha o seu grupo em Imola, na Itália, e que foi para o Brasil. Gostaria de saber por que você está aqui agora?

A minha história, eu diria, com o Roy Hart vem se emaranhando a alguns anos, quando comecei a pesquisa vocal e conheci a minha primeira professora, Germana Giannini, que imediatamente me falou do Roy Hart, e da relação que eles tinham com o corpo e com a voz. Desde então eu fiquei fascinado. Em 2011 consegui participar de uma oficina [The Human Voice - A Voz Humana], aqui no Roy Hart em Malérargues.

Aquele comigo e com Pascale (Ben).

Sim, com você e com Pascale, e eu gostei muitíssimo. Então, quando no Brasil, apareceu a oportunidade de fazer a minha pesquisa aqui, para a dissertação de mestrado eu a aproveitei imediatamente, com a ajuda de Paula [Noelia Cianfagna], que é a minha companheira e colega e que me fez a proposta quando conhecemos Linda Wise no Brasil, em um curso. Linda ministrava uma oficina ${ }^{12}$ quando the fizemos a proposta, pedimos se poderíamos fazer este projeto de intercâmbio e de pesquisa. Tivemos sorte e fomos acolhidos de braços abertos e, finalmente, estamos aqui.

Então, você gostaria de saber como é o Roy Hart Theatre hoje. Obviamente houve inúmeras e enormes mudanças, não apenas falando sobre a mudança de Londres, de onde viemos há quarenta anos para cá, França, Château de Malérargues, e reconstruímos todo o local ao longo dos anos, fazendo pesquisa vocal, criando espetáculos e dando aulas uns para os outros. Então os cursos começaram nos anos 1970... Chegamos aqui em 1974 e começamos a ministrar cursos em 1977, após a morte de Roy Hart, de Dorothy, sua esposa e de Viviane. E continuamos daí. Éramos 
quarenta e cinco pessoas quando chegamos aqui na França. E então, o que acontece hoje? Eu diria que atualmente há um concerto de seis pessoas que se chama Generation, porque se trata de pessoas... Nós seis ${ }^{13}$ estamos, assim dizemos, entre os mais idosos do Roy Hart Theatre, salvo uma que é mais jovem. Quatro de nós trabalharam anteriormente com Roy Hart mas, as outras duas nem mesmo o conheceram. Este concerto foi proposto por Sacho Wollmaier, que é um brilhantíssimo compositor, homem de uma humanidade excepcional, e que queria trabalhar exatamente com estas pessoas, a velha geração do Roy Hart Theatre. Temos ensaios um tanto intermitentes, porque todos somos ocupados com viagens, aulas etc. etc. Então, é quase um milagre que consigamos nos recolher para alguns dias de ensaio. Será na próxima semana. Trabalhamos dois dias sozinhos, um dia todos os seis, e então, quando chega Sasho, dois dias mais tarde, para trabalhar com... Não serão as seis pessoas, serão quatro ou cinco e assim é. Neste verão, como no próximo, reapresentaremos este concerto. O fizemos aqui em Malérargues em janeiro, quando fazia muito frio. Foi um grande sucesso, muito gratificante, seja para os concertistas quanto para o público. Foi uma verdadeira façanha, porque aqui faz muito frio no inverno e o aquecimento era um problema. Mas foi uma ocasião muito bonita. Então este concerto é de hoje, e vai adiante. Além disso, temos as atividades didáticas na França e no mundo do Roy Hart Theatre... os cursos começaram em Londres, antes de virmos para cá, mas os primeiros, como eu disse, os primeiros começaram em 1977.

Tivemos a tragédia da morte de Roy, Dorothy e Viviane em um acidente automobilístico... e então houve o problema de nos recolhermos e construir aqui, como eu disse... os primeiros cursos a partir de 1977 até hoje, e continuam, especialmente na primavera e verão porque é muito bonito, o lugar é belíssimo, na colina, tanta floresta, tantos rios, cachoeiras... mas, o inverno é sempre um problema. Agora somos muito menos, houve uma debandada do Roy Hart Theatre, que iniciou nos anos 1990, mais ou menos. Não sou muito boa com as datas... e vimos partir aqueles que foram para os Estados Unidos, os que foram para Lyon, na França, os que foram para Paris, ao longo dos anos. Todos eles não partiram em vão; eles também saíram para dar início aos seus centros Roy Hart. Assim, esta debandada foi interessante - porque para nós, que permanecemos aqui, foi muito difícil, porque aqueles que foram embora tinham uma outra energia para erguer os seus centros nesses outros lugares. De qualquer modo, nos mantivemos fortes e estamos aqui. No inverno têm duas pessoas aqui ${ }^{14}$, em um château que é muito grande, com dependências que reconstruímos ao longo dos anos: podemos hospedar vinte e quatro estudantes nos alojamentos e apartamentos e, na casa, outras possibilidades de alojamento para os professores. Possuímos sete estúdios com piano... ou seja, isto dá uma ideia do quanto nós reconstruímos por aqui, que era uma verdadeira ruína.

Bem, além da atividade pedagógica na França e no mundo, uma outra atividade são os cursos que demos nos anos 1970. Havia muitos franceses, no início, dentre eles tinham atores, cantores, mas também médicos, psiquiatras, fonoaudiólogos, diversas profissões, até mesmo pessoas da receita ou dos correios.

13 Kaya Anderson, lan Magilton, Saule Ryan, David Goldsworthy, Carol Mendelsohn e Marianne le Tron. 14 Kaya Anderson e Ivan Midderigh moram 0 ano todo no château, e lan Magilton mora nas redondezas. 
Isto para dar uma ideia de que aceitávamos e ainda aceitamos não só aqueles que sabem interpretar e cantar, mas também pessoas que possuem outras profissões, ou ainda donas de casa, gente sem trabalho, mas que quer e pode pagar e fazer o curso. Às vezes, temos surpresas muito boas: pessoas que pensam que não podem cantar, por exemplo, porque lhes disseram desde crianças que não podiam cantar e, então este preconceito permaneceu e permanece por toda a vida. Mas essas pessoas percebem que têm esse problema e, em pouco tempo, mesmo no curso de um final de semana, descobrem que podem cantar e que emitem vozes que não reconhecem e que, essas vozes estão conectadas com a energia... o que, ajuda essas pessoas a assumirem uma nova atitude em suas vidas. Este trabalho envolve todos de um modo particular e profundo.

Quando chegam pessoas de diversos países - como originalmente vinham do mundo inteiro - também com profissões diversas, até aquelas que não falavam japonês, chinês ou espanhol, que eu falo, havia um entendimento que se alcançava nos cursos até na parte social, quando estavam alojados aqui. Imediatamente, desde o primeiro dia. Isto dá uma ideia do que quer dizer "A Voz Humana", que esta aproximação engloba tudo aquilo que é o ser humano, e o que poderá ser. Há cantores profissionais que, de vez em quando, querem descobrir mais... afinal, somos muito conhecidos nesta área e eles não têm mais medo de perder o que já têm. Ainda que inconscientemente exista este medo constante. Cantores, atores, bailarinos e pessoas de todas as profissões.

Também temos atualmente algo mais em curso, que iniciamos quatro anos atrás: criar um programa de ensino para treinar pessoas que querem se tornar professores Roy Hart ${ }^{15}$. Este programa está sempre acontecendo: os encontros se dão três ou quatro vezes por ano, e cada um deles tem um mentor. Para se inscrever devem ter feito ao menos trezentas horas de curso e trinta horas de aulas individuais. Esta não é uma condição estabelecida pelo Roy Hart Theatre, mas é uma condição acadêmica, como também de acordo com a lei francesa.

Para quem não sabe nada, mesmo se pode consultar o nosso site ${ }^{16}$, o nosso trabalho é essencialmente a voz conectada com o corpo e com a psiqué, a mente. A ligação com tudo isso que é o ser humano, e a sua aproximação, implica num grande trabalho de observação e de escuta dos alunos. Isso produz efeitos muito eficazes que os ajudam não somente na expressão de si, que são atores ou profissionais do mundo da música ou da dança, mas também isso ajuda as pessoas a perceberem como as coisas mudam na vida quotidiana delas. Ou seja, há um lado social muito importante, as pessoas às vezes descobrem que nas relações que já têm (os maridos ou os namorados), que eu sei... às vezes pode acontecer de se separarem, porque um dos dois não tem vontade de continuar a se examinar, a questionar o que sente pelo companheiro. Mas muitas vezes as pessoas fortalecem as suas relações e descobrem novos relacionamentos e amizades que, de outro modo, não teriam nunca encontrado.

O trabalho é baseado na vida, toda a pesquisa, tudo aquilo que Alfred Wolfsohn ${ }^{17}$ obteve. Nascido na Alemanha em 1896, ele teve experiências fortíssimas e trágicas,

150 programa se chama Teacher Training. Para mais informações acesse: <http://www.roy-hart-theatre.com/site/diplomas/>

$16<$ <ttp://www.roy-hart-theatre.com/>

$17<$ http://www.roy-hart-theatre.com/> 
sendo judeu na Alemanha. Na sua infância era músico e queria tornar-se cantor. Até estourar a Primeira Guerra Mundial ele cantava em festas judias, matrimônios etc. Mas, com a guerra foi obrigado a ingressar no exército alemão. Na Primeira Guerra Mundial passou por traumas profundos e, depois, ele começou a trabalhar com pessoas que possuíam defeitos vocais, porque queria provar a sua hipótese de que todos podem cantar e que cantar ou falar é a expressão da própria personalidade, como ela é. Então, trabalhando com essas pessoas com problemas vocais, inclusive por causa de cirurgias que os fizeram perder o uso das cordas vocais, ele os fez cantar. As pessoas que não têm cordas vocais não podem pronunciar palavras, mas podem cantar e, dessa forma, ele provou para si mesmo que a sua hipótese era verdadeira e que a voz que ele chamava 'Humana' contém elementos masculinos e femininos -- assim, todos podem desenvolver essa 'Voz Humana'. Acho que é preciso muita coragem para fazer esse trabalho, porque com isso não se brinca, e a sociedade em torno sempre permaneceu - do ponto de vista do canto, com certas exceções, seja de artistas individuais que de certos grupos no mundo da música e da ópera - permaneceu muito tradicional, mesmo ouvindo-se cantores excepcionais, que cantam ópera com montagens tradicionais ou novas.

Em Londres, nos anos 1950, quando o trabalho de Alfred começava a ser reconhecido pela imprensa nacional, um jornalista inglês escreveu sobre como os compositores podem escrever essas vozes, que são novas, sobre uma série de oitavas (oito e mesmo nove oitavas), nem sempre sobre as quais se podem pronunciar palavras, mas de qualquer forma, nove oitavas (esse artigo está em arquivo).

Os compositores sempre se interessaram em compor para nós. E já houve casos, em âmbito pessoal ou em outros países, de pessoas que conseguiram fazer espetáculos utilizando o registro do Roy Hart Theatre.

Quando falo de coragem, quero dizer que não se trata apenas de adquirir uma técnica vocal, trata-se de fazer contato com o profundo de si e isto não é uma coisa óbvia. Porque existem pessoas habilidosas que podem cantar facilmente, mas, às vezes, não estão sempre em contato profundo consigo mesmas. Já possuem habilidade mas, precisam entrar em contato mais profundamente consigo mesmas. Para quem já iniciou este percurso, sabe que precisa de muita coragem porque nem tudo são rosas.

Chamamo-nos 'Roy Hart Theatre' apesar de todas as mudanças. Às vezes nos perguntam por que não nos chamamos 'Alfred Wolfsohn Theatre', isso porque, no início nos intitulamos 'Alfred Wolfsohn Roy Hart Speaker Singer' por muitos anos aqueles que falam e cantam. Após alguns anos, mesmo depois da morte de Alfred Wolfsohn, decidimos coletivamente dar o nome Roy ao teatro. Recentemente fizemos esforços para lançar mais luz sobre o trabalho de Alfred Wolfsohn e o seu nome, para que se compreenda de onde vem este trabalho. Recebemos pessoas que nem ao menos viram o site, são ignorantes e vão embora ainda ignorantes às vezes, se não temos a oportunidade de lhes informar, ou se estão fechados para a história e querem somente adquirir algo de útil e então partir.

De vez em quando, vários espetáculos e criações de ex-alunos dos cursos que se deram após a morte de Roy Hart são convidados, especialmente no verão, para apresentar os seus espetáculos. Frequentemente, a direção é feita por membros do 
Roy Hart Theatre ou do Pantheatre ${ }^{18}$. Em julho tem um simpósio do Pantheatre que é dirigido e criado pelo Roy Hart Theatre, eles têm sede aqui em Malérargues e também em Paris, eles viajam bastante.

Dentre as pessoas que convidamos ou que pedem para fazer ensaios de espetáculos e concertos, ontem à noite vimos o trabalho de um ator francês muito talentoso, que está criando este espetáculo como clown - o qual reflete sobre a estupidez do ser humano e da sociedade político-social-industrial e comenta sobre a nossa condição, especialmente aqui na Europa. Há estudantes que passam alguns meses ou até mesmo um ano para estudar, que escreveram livros - um músico holandês, um ator americano. Enfim, há a possibilidade de vir aqui para estudar conosco, compartilhar a vida por aqui e preparar um espetáculo, escrever um livro, ter a possibilidade de dialogar conosco.

Estes velhos membros que vieram para a França e participaram da reconstrução, até eles têm, de uma forma ou de outra, os seus centros (pequenos ou grandes), em diversos países, inclusive na França, em Montpellier, Lyon, Paris etc.

Alguns dos jovens professores, a nova geração, que já foram nomeados como professores Roy Hart possuem centros na Alemanha, ou nos Estados Unidos etc.

Espetáculos grandes e do passado... montamos A Tempestade de Shakespeare, fizemos muitos espetáculos na Espanha, na França, na Holanda, na Bélgica. Mas, o primeiro foi $O$ Economista, baseado no texto de um médico dramaturgo - um grande amigo nosso. Fazíamos esse espetáculo com Roy e continuamos após a sua morte, substituindo e revezando o seu papel entre nós. Mesmo esse fez turnê. Outros espetáculos se encontram no site $^{19}$.

Em O Economista éramos vinte e seis pessoas. Você pode imaginar quanto custa viajar com vinte e seis pessoas por diversos países. Agora não se pode mais pagar um preço desses. E depois, em A Tempestade, éramos uns quinze. Paglilacci, de Leoncavallo, ganhou um prêmio em Nova lorque. Iniciamos com quatorze pessoas e depois reduzimos para quatro... só para falar do passado. Agora, fora os espetáculos de verão, temos também os solos, como resultado da dinâmica da nossa história. Começamos com muitas pessoas, depois menos, até ficarmos em seis pessoas. Fomos até a América do Sul.

No passado, o nosso treino era feito cotidianamente em grupos e dirigidos por um de nós. Éramos três bailarinos que ensinavam... e outras pessoas que, ao longo dos anos, conduziam treinamentos também em música e dança baseada no clássico ou moderno. Agora que somos em menos pessoas no posto de Malérargues, exceto na primavera e verão, o treinamento é bastante individual. Cada um faz o seu treino, há quem faça Qi Gong ${ }^{20}$ e Tai Chi²1, há quem corra ou caminhe todos os dias etc. Cada um é responsável pelo seu treinamento, seja físico ou vocal.

\footnotetext{
18 Para saber mais sobre o Pantheatre acesse: <http://www.pantheatre.com/>

19 <http://www.roy-hart-theatre.com/site/the-roy-hart-theatre/>

20 Qi Gong, Qigong, Chi Kung, ou Chi gung são transliterações do termo do "chinês tradicional 氣功 [...] e literalmente significa: "Cultivo da Energia Vital". Tratase de um sistema holístico que coordena postura corporal e movimento, respiração e meditação e é praticado por suas aplicações na saúde, na espiritualidade, e no treinamento nas artes marciais. Com raízes na medicina, filosofia e artes marciais chinesas, o qigong é tradicionalmente visto como uma prática para cultivar e equilibrar o qi (chi) ou o que tem sido traduzido como "energia vital'”'. Tradução: Maria Brígida de Miranda. <https://en.wikipedia.org/wiki/Qigong>. Acesso em 10 de novembro de 2015.

21 Forma encurtada do termo transliterado para a forma brasileira Tai Chi Chuan “(太極拳) é uma arte marcial interna, chinesa, praticada tanto por seu treinamento defensivo como por seus benefícios a saúde". Tradução: Maria Brígida de Miranda. <https://en.wikipedia.org/wiki/Tai_chi>. Acesso em 10 de novembro de 2015.
} 


\section{Chorded Sound: sons nos quais se sentem os acordes de notas.}

Estes sons podem ser sentidos pelo Roy Hart nas gravações, nas quais se podem distinguir as notas dos acordes. Para fazer estes sons é necessário uma concentração excepcional. Depois de Roy, muitos outros fazem estes sons. Alguns são interessantes. Na minha opinião... minha descrição pessoal, [Chorded Sound] contém as forças opostas: céu e terra, amor e ódio. Estas forças opostas são universais, influenciam todos... todos os seres humanos.

Se quiser falar sobre o canto harmônico. Porque você fez canto harmônico. Talvez possamos dialogar um pouco.

Sim, o canto harmônico foi uma paixão que surgiu em 2004, quando fazíamos um espetáculo sobre Città Invisibili, de Italo Calvino. Havia diálogos ente Marco Polo e Kublai Kahn, então comecei a me apaixonar pelos cantos mongóis, pelos cantos tibetanos, todos aqueles cantos que vinham, de qualquer forma, da região de Kublai Kahn e fiquei fascinado por esses cantos harmônicos, justamente porque produziam, contemporaneamente, vários sons de uma mesma pessoa.

Comecei a reproduzi-los um pouco às cegas, buscando um pouco a imitação. Depois procurei, sempre com a ajuda dos professores que encontrei ao longo dos anos - dentre os quais Germana Giannini encontrar sempre pessoas que tiveram experiência com o canto harmônico como Andrea De Luca e Tran Quang Hai. Ao ouvir os Chorded Sound de Roy Hart, encontrei algumas semelhanças - porque existem técnicas variadas de canto harmônico que produzem diversos tipos de sonoridades e que sempre me fascinaram. Essa, além das outras coisas do Roy Hart e também coisas que me lembravam o canto harmônico. Isso tudo me despertou a curiosidade, além de me fascinar com as outras coisas que o Roy Hart fazia.

E isto te fascinou, conduziu você até o Roy Hart porque sentia uma conexão com aquele canto harmônico.

Sim, sim, também.

O meu comentário é que, ao longo dos anos, aquele trabalho que eu fiz com Alfred Wolfsohn e com Roy Hart, que ainda se faz, se descobre às vezes nas aulas de canto, as quais frequentemente estou ao piano. Mas nem sempre as vozes mundiais de tantas raças do mundo emergiam nessas aulas de canto, que é uma coisa extraordinária, porque não se considerava: "agora se canta africano... ou russo... ou tibetano", mas assim saiam. Exatamente assim o tibetano aconteceu comigo. Emergiu uma voz que é bem dos tibetanos, dos sacerdotes, dos monges tibetanos. Primeiro fiz nas aulas com Roy Hart e quando eu fiz esses sons, essas vozes, eu me senti profunda, larga, alta como se fosse o mar, senti-me verdadeiramente íntegra. Alfred Wolfsohn sempre me 
dizia: "Esses sons você poderá repetir, são uma força que poderá... que te nutrirá."

Então, esse era o meu comentário para você, que me contou do canto harmônico e da sua experiência... e a experiência das nossas aulas de canto, nas quais emergem estas vozes de tantos países, raças e tipos diversos, com resultados deveras excitantes. Porque quando você descobre que do corpo saem essas vozes - as quais você nunca havia planejado e outros escutam e dizem: "esta seguramente é uma voz africana, ou tibetana" - isso é a prova. Karl Gustav Jung a descobriu na psicologia: que todo ser humano de qualquer raça no mundo, os arquétipos e os sonhos possuem estruturas muito similares entre si. Alfred Wolfsohn provou que a esses arquétipos podem ser dadas 'vozes'. Podem 'ser dadas vozes aos arquétipos'. Então, não apenas fazer pinturas, escritos e outras coisas, mas também exprimir vocalmente os arquétipos, porque essa é uma grande possibilidade de restauração do ser humano. Porque frequentemente não se ousa chamar as 'forças poderosas' que existem em cada ser humano.

Gostaria apenas de mencionar que agora possuímos os arquivos em Cds e DVDs, que podem ser enviados até mesmo por solicitação. Há também a possibilidade de reservas, quando as pessoas estão aqui, de ouvir as gravações e temos pessoas que cuidam delas.

Sobre os livros que existem a respeito de Roy Hart: existe o Dark Voices - que é em inglês, e atualmente estamos traduzindo também para o francês - em italiano seria Voci Oscure. Outros livros são: The Mistery of the Voice, escrito em inglês e La Voix de l'inahuit (A Voz do Não Ouvido). Além disso existem as conferências, ensaios, velhos jornais do Roy Hart Theatre (que nós não fazemos mais), mas são interessantes.

Muito importantes são os manuscritos de Alfred Wolfsohn, que nunca foram publicados, mas ele os mandava, às vezes, para o mundo, para algumas pessoas que se interessavam. Um dos seus trabalhos se chama A Ponte e o outro se chama Orfeu. O fato de não serem publicados não foi por falta de tentativas. Há décadas, grupos ou pessoas, de um modo geral, acham difícil aceitar um trabalho sobre a voz que contenha todos os elementos do ser humano: o lado físico, o lado mental, o lado metafísico etc. e o biológico. Pois, o trabalho comporta até uma mudança biológica e não somente mental. Somado a esse fato, existe uma filosofia - que eu diria, a filosofia de Alfred Wolfsohn - a ideia de que se possa redimir as experiências ruins do passado. É como na alquimia, onde se procurava transformar a matéria bruta em ouro. Mesmo essas experiências ruins, por meio de um processo de trabalho - não num final de semana, mas num processo longo, de anos - podem redimir aquilo que continua a nos incomodar ou que aparece nos sonhos (aqueles que nós esquecemos). Isso é possível ao cantar, ao confrontar-se também com os outros. No processo de trabalho e treinamento essas experiências do passado progressivamente reduzirem a sua força... as experiências ruins, quero dizer. A criatividade que pode emergir de qualquer pessoa, segundo as circunstâncias do contexto... Talvez, seja necessário muito tempo... ou talvez as forças emerjam imediatamente com o trabalho vocal. 